\title{
A Spectral-SAR Model for the Anionic-Cationic Interaction in Ionic Liquids: Application to Vibrio fischeri Ecotoxicity
}

\author{
Ana-Maria Lacrămă ${ }^{1,2}$, Mihai V. Putz ${ }^{3, *}$ and Vasile Ostafe ${ }^{2}$ \\ 1 Institute of Chemistry Timişoara of the Romanian Academy, 24 Mihai Viteazul Avenue, RO- \\ 300223, Timişoara, Romania \\ 2 Laboratory of Biochemistry, Chemistry Department, West University of Timişoara, Pestalozzi Street \\ No.16, Timişoara, RO-300115, Romania \\ 3 Laboratory of Computational and Structural Physical Chemistry, Chemistry Department, West \\ University of Timişoara, Pestalozzi Street No.16, Timişoara, RO-300115, Romania \\ * Author to whom correspondence should be addressed; E-mail: mvputz@cbg.uvt.ro or \\ mv_putz@yahoo.com; Web: www.cbg.uvt.ro/mvputz.
}

Received: 25 July 2007; in revised form: 15 August 2007 / Accepted: 17 August 2007 /

Published: 23 August 2007

\begin{abstract}
Within the recently launched the spectral-structure activity relationship (S-SAR) analysis, the vectorial anionic-cationic model of a generic ionic liquid is proposed, along with the associated algebraic correlation factor in terms of the measured and predicted activity norms. The reliability of the present scheme is tested by assessing the Hansch factors, i.e. lipophylicity, polarizability and total energy, to predict the ecotoxicity endpoints of wide types of ionic liquids with ammonium, pyridinium, phosphonium, choline and imidazolium cations on the aquatic bacteria Vibrio fischeri. The results, while confirming the cationic dominant influence when only lipophylicity is considered, demonstrate that the anionic effect dominates all other more specific interactions. It was also proved that the S-SAR vectorial model predicts considerably higher activity for the ionic liquids than for its anionic and cationic subsystems separately, in all considered cases. Moreover, through applying the least norm-correlation path principle, the complete toxicological hierarchies are presented, unfolding the ecological rules of combined cationic and anionic influences in ionic liquid toxicity.
\end{abstract}

Keywords: S-SAR, vectorial summation, algebraic correlation factor, the least path principle. 


\section{Introduction}

Since their emergence a decade ago, ionic liquids (IL) have had a constantly growing influence on organic, bio- and green chemistry, due to the unique physico-chemical properties manifested by their typical salt structure: a heterocyclic nitrogen-containing organic cation (in general) and an inorganic or organic anion [1], with melting points below $100{ }^{\circ} \mathrm{C}$ and no vapor pressure [2]. The latter property leads to the practical replacement of conventional volatile organic compounds (VOCs) from the point of view of atmospheric emissions, though they do present the serious drawback that a small amount of IL could enter the environment through groundwater [3]. This risk makes it necessary to perform further eco-toxicological studies of IL on various species, in order to improve the "design rules" for synthesized IL with minimal toxicity to environment integrated organisms.

Ionic liquids display variable stability in terms of moisture and solubility in water, polar and nonpolar organic solvents [4]. Various values of ionic liquid hydrophobicity and polarity may be tailored [3] with the help of nucleoside chemistry [5] according to the main principles of green chemistry [6,7]: the new chemicals must be designed to preserve effectiveness of function while reducing toxicity, and not persisting in the environment at the end of their usage, but breaking down into inoffensive degradation products.

Most of the ionic liquids with imidazolium, phosphonium, pyridinium and ammonium that were tested were resistant to ready biodegradation [8]. Their toxicity to microorganisms can limit biodegradation, while their toxicity to humans and others organisms is obviously significant. The examination regarding the biodegradation of surfactant compounds focuses on a close resemblance between many quaternary ammonium compounds as well as surfactants based around an imidazolium core. The factors that improved the biodegradation of surfactants have successfully been applied to ionic liquids. For instance, bis(trifluoromethylsulfonyl)imide (TFMSi) and PF6 ionic liquids containing an ester in the side chain exhibit the same hydrophobic character as 1-n-butyl-3-methylimidazolium bis(trifluoromethylsulfonyl)imide ([BMIM][TFMSi]) and 1-n-butyl-3-methylimidazolium hexafluorophosphate ([BMIM][PF6]). The enzymatic hydrolysis step, which initiates a pathway to further breakdown products, improves the biodegradation. Therefore, compound stability and toxicity are the factors biodegradability depends on. The effect of the counter-ion was not noticeable in biodegradability even though modifications of the anion led to changes in physical and chemical properties. Still, the introduction of an organic anion clearly improves the extent of ultimate biodegradation [9].

From the point of view of reactivity, IL generally do not coordinate to metal complexes, enzymes and different organic substrates [10]; however, they are usually the major component of the mixtures having pre-organized structures with the aid of many hydrogen bonds (structural directionality) in contrast to classical salts in which the compounds are mostly formed with the aid of ionic bonds (charge-ordering structures) [11,12].

On the other way, the recycling ability of IL, especially dialkyl-imidazolium based ionic liquids (the most studied until now), is based on their lack of solubility in some key organic solvents (e.g. diethyl ether) and in water - for the special case of 1-n-butyl-3-methylimidazolium hexafluorophosphate ([BMIM][PF6]). Water/soluble ionic liquids are more difficult to recycle, since their water immiscible complements, the secondary products, cannot be easily removed [13]. 
The detailed examination of relative energies and structural interactions (like ion position, $\mathrm{H}$-bonding and anion conformational variability) in gas-phase ion-pairs has emphasized the way these quantities can be used to build up a picture of the local structure and interactions occurring in ionic liquids. For instance, while 1-n-butyl-3-methylimidazolium chloride ([BMIM][Cl]) forms a highly connected liquid with relatively strong interactions - at one extreme, and 1-n-butyl-3methylimidazolium bis(trifluoromethylsulfonyl)imide ([BMIM][TFMSi]) forms a low connectivity network of weakly linked ions - at the other extreme, [BMIM][BF4] lying between these two extremes forms a weak but more regular network. Melting points and viscosity are partly dependent on local interactions between an ion and other molecules in the first solvation shell. For imidazolium based cations, nine sites of interactions are preferred by the anion [14]. Hunt et al proved that the hydrogen bond is primarily ionic with a moderate covalent character [15]. The fact that the Coulombic attraction is the dominant stabilization force was demonstrated by the analysis of the charge distribution, molecular orbitals and electron density of the dimer complex 1-n-butyl-3-methylimidazolium chloride ([BMIM][Cl]): the interactions governing the top conformers are very different from those in which the $\mathrm{Cl}$ anion remains in plane (were $\mathrm{Cl}$ anion interacts with the $\pi$ manifold of orbitals); the ion-pair LUMO is the cation anti-bonding LUMO and thus electron acceptance is not favorable [15]. The effect of the chloride anion on rotation of the butyl chain is investigated and found to lower some rotational barriers while enhancing others [16]. Since the Coulombic forces are significant in an ionic liquid, charge distribution or point charges on the constituent ions are likely to be more significant than in liquids made up of neutral charge molecules [17] and deserve a more detailed study.

In this respect, the costs of all approaches for sustainable product design can be reduced using SAR and QSAR methods [18]. It has already been proved that the anti-microbial activity of quaternary ammonium chlorides is lipophilicity-dependent [19]. While the 1-octanol-water partition coefficient could be seen only as the first approximation for compound lipophylicity, bioaccumulation and toxicity in fish, as well as sorption to soil and sediments assumes that lipophylicity is the main factor of anti-microbial activity [20]. Nevertheless, aiming at a deeper understanding of the specific mechanistic description of IL eco-toxicity, it is worth considering that the ionic liquid properties are more comprehensively quantified through lipophylicity, polarizability and total energy as a unitarily complex of factors in developing appropriate structure-activity relationship (SAR) studies.

However, the main problem in assessing the viable QSAR studies to predict ionic liquid toxicities concerns the anionic-cationic interaction superimposed on the anionic and cationic subsystems containing ionic liquids. There are basically two complementary ways of attaining this goal. One may address the search of special rules for assessing the anionic-cationic structural separately from the individual anionic and cationic ones, and then generating the QSAR models. Yet, because the cationic and anionic effects on liquid toxicity are merely separately studied at the moment, the appropriate strategy would be to firstly derive the anionic and cationic QSARs and only then to move on to a QSAR of the ionic liquid viewed as an anionic-cationic interaction. The current paper shows, for the first time, how the latter procedure may be implemented by means of the vectorial approach of the spectral-SAR analysis. The illustration of the S-SAR-IL model presented is performed by studying the aquatic bacteria Vibrio fischeri toxicity against a list of twenty-two ionic liquids, appropriately chosen so that they should contain a wide variety of heads, side chains, and anions. This way, the present 
methodology and results may be extended over a wide range of organisms towards designing specific eco-toxicological ionic liquid batteries.

\section{The Spectral-SAR Ionic Liquid (S-SAR-IL) Model}

Although ionic liquid structure is currently defined through three types of substructures, the head group (the positively charged moiety) with the side chain, R1, R2, etc., which are substituents on heads group, and the anion [7], the present approach views IL as consisting mainly of its cationic (head and side chain) and anionic subsystems in mutual interaction. This way, the two sub-systems containing ionic liquid can be modeled through their vectorial activities that sum up into the predicted activity of the ionic liquid as a whole. This picture is further sustained by the possibility of employment of the Spectral-SAR method to the present purposes.

\subsection{S-SAR Concepts}

Without going into details [18], if one has to solve the correlation between a set of biological activities of $N$-compounds with the set of $M$-structural properties of each of them,

$$
|Y\rangle=b_{0}\left|X_{0}\right\rangle+b_{1}\left|X_{1}\right\rangle+\ldots+b_{k}\left|X_{k}\right\rangle+\ldots+b_{M}\left|X_{M}\right\rangle
$$

a spectral algebraic algorithm can be applied based on the vectorial view of the descriptors and measured activity combined with the Gram-Schmidt orthogonalization recipe and on the scalar product rule

$$
\left\langle\Psi_{l} \mid \Psi_{k}\right\rangle=\sum_{i=1}^{N} \psi_{i l} \psi_{i k}=\left\langle\Psi_{k} \mid \Psi_{l}\right\rangle
$$

giving out a real number from any two arbitrary $N$-dimensional vectors

$$
\left|\Psi_{l}\right\rangle=\left|\begin{array}{llll}
\psi_{1 l} & \psi_{2 l} & \ldots & \psi_{N l}
\end{array}\right\rangle,\left|\Psi_{k}\right\rangle=\left|\begin{array}{llll}
\psi_{1 k} & \psi_{2 k} & \ldots & \psi_{N k}
\end{array}\right\rangle
$$

Table 1: The vectorial descriptors in a Spectral-SAR analysis.

\begin{tabular}{ccccccc}
\hline \hline Activity & \multicolumn{6}{c}{ Structural predictor variables } \\
\hline$|Y\rangle$ & $\left|X_{0}\right\rangle$ & $\left|X_{1}\right\rangle$ & $\ldots$ & $\left|X_{k}\right\rangle$ & $\ldots$ & $\left.X_{M}\right\rangle$ \\
\hline$y_{1}$ & 1 & $x_{11}$ & $\ldots$ & $x_{1 k}$ & $\ldots$ & $x_{1 M}$ \\
$y_{2}$ & 1 & $x_{21}$ & $\ldots$ & $x_{2 k}$ & $\ldots$ & $x_{2 M}$ \\
$\vdots$ & $\vdots$ & $\vdots$ & $\vdots$ & $\vdots$ & $\vdots$ & $\vdots$ \\
$y_{N}$ & 1 & $x_{N 1}$ & $\ldots$ & $x_{N k}$ & $\ldots$ & $x_{N M}$ \\
\hline \hline
\end{tabular}

Let's also note that when considering the $N$-biological activities as well as their respective predictor variables grouped into vectors, as displayed in Table 1, the unity vector $\left|X_{0}\right\rangle=\left|\begin{array}{llll}1 & 1 & \ldots & 1\end{array}\right\rangle$ was added to account for the free correlation term in (1). 
Actually, the S-SAR equation is derived from the determinant [18]:

$$
\left|\begin{array}{ccccccc}
|Y\rangle & \omega_{0} & \omega_{1} & \cdots & \omega_{k} & \cdots & \omega_{M} \\
\left|X_{0}\right\rangle & 1 & 0 & \cdots & 0 & \cdots & 0 \\
\left|X_{1}\right\rangle & r_{0}^{1} & 1 & \cdots & 0 & \cdots & 0 \\
\vdots & \vdots & \vdots & \vdots & & \vdots & \\
\left|X_{k}\right\rangle & r_{0}^{k} & r_{1}^{k} & \cdots & 1 & \cdots & 0 \\
\vdots & \vdots & \vdots & \vdots & & \vdots & \\
\left|X_{M}\right\rangle & r_{0}^{M} & r_{1}^{M} & \cdots & r_{k}^{M} & \cdots & 1
\end{array}\right|=0
$$

once it is expanded along its first column, and where

$$
r_{i}^{k}=\frac{\left\langle X_{k} \mid \Omega_{i}\right\rangle}{\left\langle\Omega_{i} \mid \Omega_{i}\right\rangle}, \omega_{k}=\frac{\left\langle\Omega_{k} \mid Y\right\rangle}{\left\langle\Omega_{k} \mid \Omega_{k}\right\rangle},\left|\Omega_{k}\right\rangle=\left|X_{k}\right\rangle-\sum_{i=0}^{k-1} r_{i}^{k}\left|\Omega_{i}\right\rangle, k=\overline{0, M} .
$$

With these ingredients the QSAR equation (1) becomes operational, with all coefficients effectively worked out. However, besides the effectiveness of the S-SAR methodology in reproducing the oldfashioned multi-linear QSAR analysis, one of its advances concerns the possibility of introducing norms associated with either predicted (computed) or experimental (measured) activities,

$$
\| Y\rangle \|=\sqrt{\langle Y \mid Y\rangle}=\sqrt{\sum_{i=1}^{N} y_{i}^{2}}
$$

thus gaining the possibility of the unique assignment of a number to a specific type of correlation, i.e. performing a sort of final quantification of the models. Nevertheless, the activity norm given in Eq. (6) opens the possibility of replacing the classical statistical correlation factor

$$
r_{S-S A R}^{\text {STATISTIC }}=\sqrt{1-\frac{\sum_{i=1}^{N}\left(y_{i E X P}-y_{i}\right)^{2}}{\sum_{i=1}^{N}\left(y_{i E X P}-\frac{1}{N} \sum_{i=1}^{N} y_{i E X P}\right)^{2}}}
$$

with a new definition, introducing the so called algebraic S-SAR correlation factor as the ratio of the spectral norm of the predicted activity versus that of the measured one:

$$
r_{S-S A R}^{A L G E B A I C}=\sqrt{\frac{\sum_{i=1}^{N} y_{i}^{2}}{\sum_{i=1}^{N} y_{i E X P}^{2}}}
$$

In fact this new correlation factor definition compares the vectorial lengths of the predicted activity against the measured one, thus being an indicator of the extent to which certain computed property or activity approaches the "dimension" of the observed quantity. However, it was also shown that 
practically the algebraic correlation factor (8) furnishes higher values than its statistical counterpart definition (7), in a systematical manner [18], thus making it the ideal tool for the present attempt to consider the ionic liquid activity taken from its cationic and anionic sub-system ones.

Moreover, with the help of both spectral norms and correlation factors we can introduce the so called the least path principle in terms of paths between the tested models (or endpoints) [18]:

$$
\delta[A, B]=0 ; \quad A, B: \text { ENDPOINTS }
$$

with

$$
[A, B]=\sqrt{\left.\left(\|\left|Y^{B}\right\rangle\|-\| Y^{A}\right\rangle \|\right)^{2}+\left(r_{B}^{\text {STALEBRAIC }}-r_{A}^{\text {STALEBRAICIC }}\right)^{2}}
$$

thus providing a practical tool for deciding the dominant hierarchies along the possible ones with the important consequence of picturing the mechanistic and almost temporal evolution of structural causes that trigger the observed effects. This methodology was successfully applied in ecotoxicology [18] and for designing the behavior of the species interactions within a test battery [21], promising to furnish the frame also in ionic liquids analysis.

\subsection{S-SAR for Ionic Liquids}

Basically, since we may consider the ionic liquid as composed by the anionic and cationic subsystems, we can employ the spectral vectorial space of anionic and cationic activities to form the ionic liquid one throughout the vectorial resultant

$$
\left|Y_{A C}\right\rangle=\left|Y_{C}\right\rangle+\left|Y_{A}\right\rangle
$$

as displayed also in Figure 1.

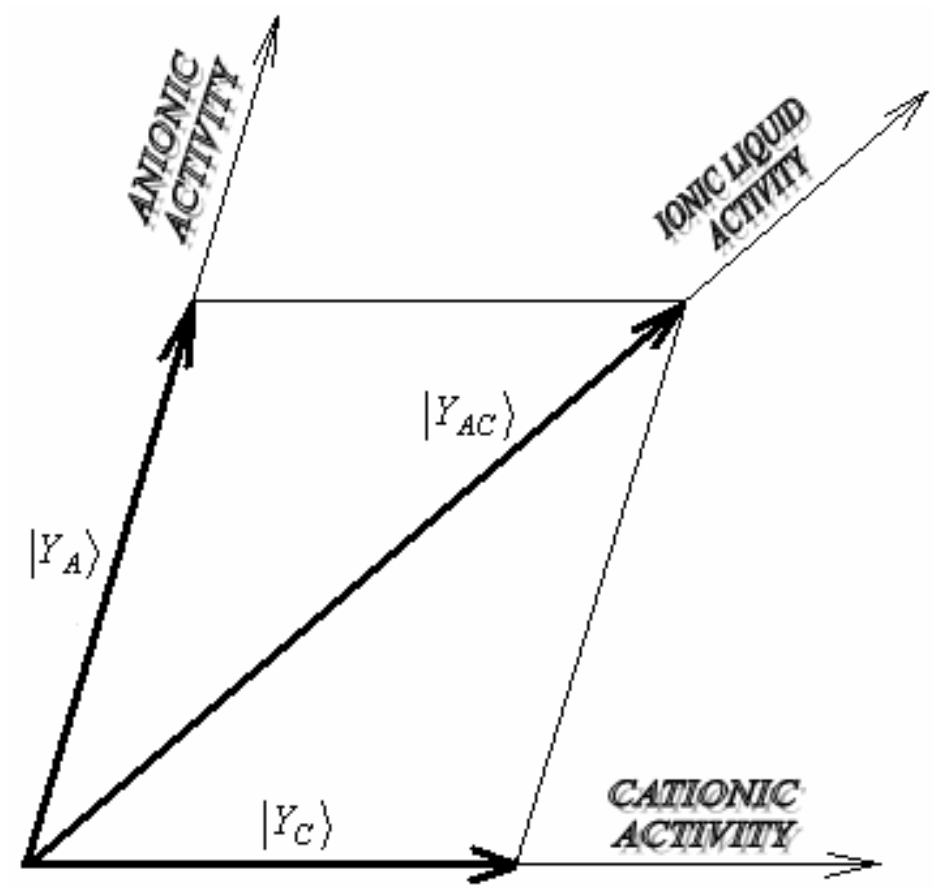

Figure 1: The vectorial summation of the cationic and anionic activities in ionic liquids. 
The vectorial summation in (11) may also be seen as the interference of the anionic and cationic activities in the space of ionic liquid so that their mutual interaction is included. Actually, searching for the predicted norm of the vectorial ionic liquid activity

$$
\left.\| Y_{A C}\right\rangle \|=\sqrt{\left\langle Y_{A C} \mid Y_{A C}\right\rangle}=\sqrt{\sum_{i=1}^{N} y_{i A C}^{2}}
$$

one can notice the interference effects between the anionic and cationic systems

$$
\left.\| Y_{A C}\right\rangle \|=\sqrt{\left.\left.\left.\| Y_{C}\right\rangle\left\|^{2}+\right\| Y_{A}\right\rangle\left\|^{2}+2\right\| Y_{C}\right\rangle\|\|\left|Y_{A}\right\rangle \| \cos \theta_{A C}}
$$

through the correlation angle between the associated vectors, $\cos \theta_{A C}$. Nevertheless, its practical definition can be achieved, since the anionic-cationic norm (13) is rewritten employing the vectorial relation (11) to the scalar product between the anionic and cationic vectors

$$
\left.\| Y_{A C}\right\rangle \|=\sqrt{\left.\left.\| Y_{C}\right\rangle\left\|^{2}+\right\| Y_{A}\right\rangle \|^{2}+2\left\langle Y_{C} \mid Y_{A}\right\rangle}
$$

Now, from the two equivalent expressions (13) and (14), the anionic-cationic correlation angle results in a numerical form from the vectorial components of the anionic and cationic activities

$$
\cos \theta_{A C}=\frac{\sum_{i=1}^{N} y_{i C} y_{i A}}{\sqrt{\sum_{i=1}^{N} y_{i C}^{2} \sum_{i=1}^{N} y_{i A}^{2}}}
$$

Basically, the degree of anionic-cationic activity interaction in ionic liquid is fixed by the value of the angle (15) for each envisaged QSAR model or endpoint.

Finally, aiming to obtain the ionic liquid working QSAR equation from the cationic and anionic counterparts one simply needs to expand the norm and the scalar product in (14) as the square sum of components, according to the norm and scalar product definitions (12) and (2), respectively, with the intermediate result:

$$
\sqrt{\sum_{i=1}^{N} y_{i A C}^{2}}=\sqrt{\sum_{i=1}^{N} y_{i C}^{2}+\sum_{i=1}^{N} y_{i A}^{2}+2 \sum_{i=1}^{N} y_{i C} y_{i A}}
$$

Hence, by the direct identification of right and left side terms the quested equation arises

$$
y_{i A C}=\sqrt{y_{i C}^{2}+y_{i A}^{2}+2 y_{i C} y_{i A}}=y_{i C}+y_{i A}
$$

With these all the required concepts and analytical tools are given for that any ionic liquid anioniccationic interaction and resulted activity analysis on certain species or organism be performed, while concrete example will in next be exposed. 


\section{Application to Ecotoxicology}

\subsection{The Working System}

Usually, the classical assessment of new industrial chemicals is inflexible, being directed by regulations and standardized procedures, while biological test systems are very expensive and the costs increase with the number of new chemicals released. So, a flexible test strategy is needed in correlating the chemical compounds with the systems they act upon. Although qualitative (eco) toxicological algorithms for selection of test systems have been proposed in terms of identification of individual effects of different head-groups (with identical side chains and anions) and different anions (with identical cations) [7], a quantitative theoretical prediction algorithm for tested compounds in biological systems is still need be proposed due the lack of readily accessible ecotoxicological data [8].

The principles of green chemistry say that one has to consider the whole process (life cycle analysis) rather than individual components of reaction (single issue sustainability), based on the fact that the acute toxicity measurements do not provide a complete characterization of the full impact of a substance release into environment, but are only part of the environmental impact assessment [6, 8].

In this context, ionic liquids with cations like pyridinium, imidazolium and pyrrolidinium have already been nominated in the United States National Toxicology Program (NTP) for toxicological testing based upon their potential of new solvents but also due they ability to enter in aquatic system [22]; if an accidentally discharge of ionic liquids into water occur, many of them being water soluble, they may be an environmental risk to aquatic plants and animals [23].

For this reason the current application will develop the S-SAR complete algorithm up to the mechanistic prediction of the correlated structural causes and ecotoxicological effects for the ionic liquids of Figure 2, containing ammonium, pyridinium, phosphonium, choline, and imidazolium cations, on aquatic bacteria Vibrio fischeri [24]. Whereas the Vibrio fisheri species was previously found to be one of the most resistant species to ordinary phenol compounds toxicity [21], the present ionic liquids show quite a wide structural variety to furnish useful information of their environmental action. The cationic and anionic structural properties, the lipophylicity, the electronic polarizability and the total energy, where computed with the HyperChem computational environment [25] and displayed in Table 2 together with the reported measured activity of their containing ionic liquids, respectively.

The data in Table 2 are suitable arranged so that the S-SAR analysis is performed successively at the cationic and anionic level and then at the ionic liquid levels based on equations (4)-(10) and (15)(17) in a Hansch type expansion:

$$
A=f_{\text {Linear }}\left(\log P, P O L, E_{T O T}\right),
$$

when accounting for different combinations between the lipophylicity (hydrophobic character), polarizability (electronic character) and total energy (steric character) factors, respectively. The spectral hierarchy of the predicted activities with respect to different concerned endpoints would lead to the mechanistic scheme according with the cationic and anionic sides as well as the overall ionic liquids influences the environmental (Vibrio fischeri) toxicity. 

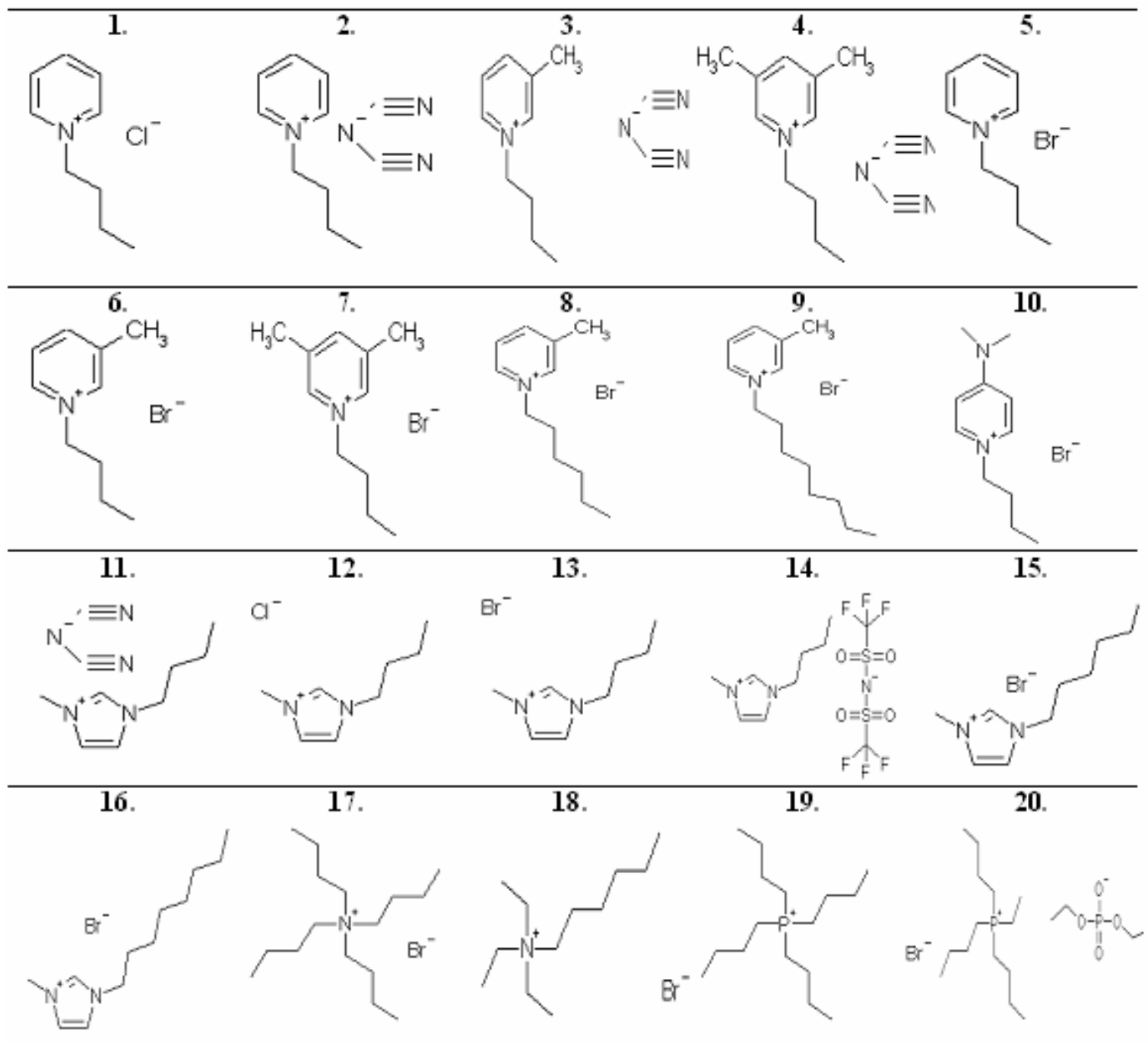

21.

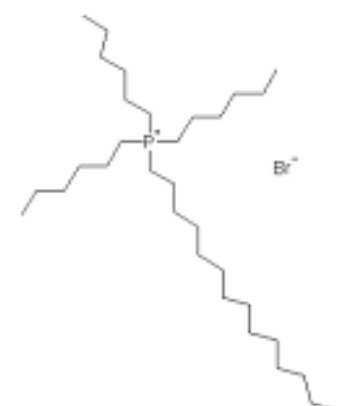

22.

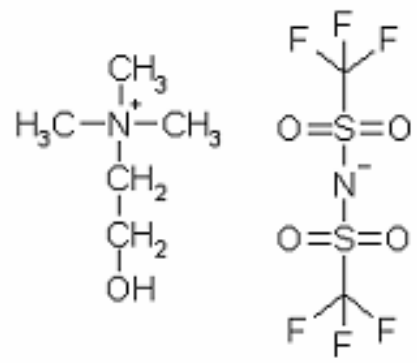

Figure 2: The ionic liquids acting on Vibrio fischeri species studied in this work. 
Table 2: The series of the ionic liquids of Figure 2 of those toxic activities $\boldsymbol{A}=\log \left(\mathrm{EC}_{50}\right)$ on Vibrio fischeri were considered [24], with the marked values taken from [4], along structural parameters $\log P, P O L\left(\AA^{3}\right)$, and $E_{T O T}(\mathrm{kcal} / \mathrm{mol})$ as accounting for the hydrophobicity, electronic (polarizability) and steric (total energy at optimized 3D geometry) effects, computed with the help of HyperChem program [25], for each cation and anion containing ionic liquid, respectively.

\begin{tabular}{|c|c|c|c|c|c|c|c|c|}
\hline \multirow{2}{*}{ No. } & \multirow{2}{*}{ NAME } & \multirow{2}{*}{$\begin{array}{r}\mathbf{A}_{\text {exp }} \\
\left|Y_{E X P}\right\rangle\end{array}$} & \multicolumn{2}{|c|}{$\log P$} & \multicolumn{2}{|c|}{ Polarizability } & \multicolumn{2}{|c|}{ TOTAL ENERGY } \\
\hline & & & $\begin{array}{l}\text { CAT. } \\
\left|X_{1 C}\right\rangle\end{array}$ & $\begin{array}{l}\text { AN. } \\
\left|X_{1 A}\right\rangle\end{array}$ & $\begin{array}{l}\text { CAT. } \\
\left|X_{2 C}\right\rangle\end{array}$ & $\begin{array}{l}\text { AN. } \\
\left|X_{2 A}\right\rangle\end{array}$ & $\begin{array}{l}\text { CAT. } \\
\left|X_{3 C}\right\rangle\end{array}$ & $\begin{array}{l}\mathbf{A N} . \\
\left|X_{3 A}\right\rangle\end{array}$ \\
\hline 1. & $\begin{array}{l}\text { 1-n-butylpyridinium } \\
\text { chloride }\end{array}$ & $0.41^{*}$ & 2.85 & 0.63 & 17.51 & 2.32 & -250008.14 & -285190.78 \\
\hline 2. & $\begin{array}{l}\text { 1-n-butylpyridinium } \\
\text { dicyanoamide }\end{array}$ & $0.31 *$ & 2.85 & 0.43 & 17.51 & 5.51 & -250008.14 & -147935.98 \\
\hline 3. & $\begin{array}{l}\text { 1-n-butyl-3-methylpyridinium } \\
\text { dicyanoamide }\end{array}$ & $-0.34^{*}$ & 3.32 & 0.43 & 19.35 & 5.51 & -274222.62 & -147935.98 \\
\hline 4. & $\begin{array}{l}\text { 1-n-butyl-3,5-dimethylpyridinium } \\
\text { dicyanoamide }\end{array}$ & $-0.62^{*}$ & 3.78 & 0.43 & 21.18 & 5.51 & -298437.03 & -147935.98 \\
\hline 5. & $\begin{array}{l}\text { 1-n-butylpyridinium } \\
\text { bromide }\end{array}$ & $0.40^{*}$ & 2.85 & 0.94 & 17.51 & 3.01 & -250008.14 & -1596918.25 \\
\hline 6. & $\begin{array}{l}\text { 1-n-butyl-3-methylpyridinium } \\
\text { bromide }\end{array}$ & $-0.25^{*}$ & 3.32 & 0.94 & 19.35 & 3.01 & -274222.62 & -1596918.25 \\
\hline 7. & $\begin{array}{l}\text { 1-n-butyl-3,5-dimethylpyridinium } \\
\text { bromide }\end{array}$ & $-0.31^{*}$ & 3.78 & 0.94 & 21.18 & 3.01 & -298437.03 & -1596918.25 \\
\hline 8. & $\begin{array}{l}\text { 1-n-hexyl-3-methylpyridinium } \\
\text { bromide }\end{array}$ & $-0.94 *$ & 4.11 & 0.94 & 23.02 & 3.01 & -322641.81 & -1596918.25 \\
\hline 9. & $\begin{array}{l}\text { 1-n-octyl-3-methylpyridinium } \\
\text { bromide }\end{array}$ & $-2.21^{*}$ & 4.90 & 0.94 & 26.69 & 3.01 & -371060.81 & -1596918.25 \\
\hline 10. & $\begin{array}{l}\text { 1-n-butyl-4- } \\
\text { dimethylaminopyridinium bromide }\end{array}$ & -0.68 & 3.11 & 0.94 & 22.53 & 3.01 & -332525.97 & -1596918.25 \\
\hline 11. & $\begin{array}{l}\text { 1-n-butyl-3-methylimidazolium } \\
\text { dicyanoamide }\end{array}$ & $0.67^{*}$ & 0.68 & 0.43 & 17.22 & 5.51 & -260646.64 & -147935.98 \\
\hline 12. & $\begin{array}{l}\text { 1-n-butyl-3-methylimidazolium } \\
\text { chloride }\end{array}$ & $0.71^{*}$ & 0.68 & 0.63 & 17.22 & 2.32 & -260646.64 & -285190.78 \\
\hline 13. & $\begin{array}{l}\text { 1-n-butyl-3-methylimidazolium } \\
\text { bromide }\end{array}$ & $1.01^{*}$ & 0.68 & 0.94 & 17.22 & 3.01 & -260646.64 & -1596918.25 \\
\hline 14. & $\begin{array}{l}\text { 1-n-butyl-3-methylimidazolium } \\
\text { bis(trifluoromethanesulfonyl)imide }\end{array}$ & 0.39 & 0.68 & 3.05 & 17.22 & 7.20 & -260646.64 & -1128283.62 \\
\hline 15. & $\begin{array}{l}\text { 1-n-hexyl-3-methylimidazolium } \\
\text { bromide }\end{array}$ & $-1.58^{*}$ & 1.47 & 0.94 & 20.89 & 3.01 & -309065.84 & -1596918.25 \\
\hline 16. & $\begin{array}{l}\text { 1-n-octyl-3-methylimidazolium } \\
\text { bromide }\end{array}$ & $-2.37 *$ & 2.26 & 0.94 & 24.56 & 3.01 & -357484.59 & -1596918.25 \\
\hline 17. & $\begin{array}{l}\text { tetrabutylammonium } \\
\text { bromide }\end{array}$ & 0.27 & 4.51 & 0.94 & 30.91 & 3.01 & -422421.97 & -1596918.25 \\
\hline 18. & $\begin{array}{l}\text { hexyltriethylammonium } \\
\text { bromide }\end{array}$ & -0.54 & 2.71 & 0.94 & 23.57 & 3.01 & -325587.25 & -1596918.25 \\
\hline 19. & $\begin{array}{l}\text { tetrabutylphosphonium } \\
\text { bromide }\end{array}$ & -0.29 & 2.89 & 0.94 & 30.91 & 3.01 & -600149.62 & -1596918.25 \\
\hline 20. & $\begin{array}{l}\text { tributylethylphosphonium } \\
\text { diethylphosphate }\end{array}$ & 0.07 & 2.02 & 2.63 & 27.24 & 10.53 & -551729.87 & -494172.37 \\
\hline 21. & $\begin{array}{l}\text { Trihexyl(tetradecyl)phosphonium } \\
\text { bromide }\end{array}$ & 0.41 & 9.23 & 0.94 & 60.27 & 3.01 & -987499.25 & -1596918.25 \\
\hline 22. & $\begin{array}{l}\text { Choline } \\
\text { bis(trifluoromethanesulfonyl)imide }\end{array}$ & 1.15 & -0.76 & 3.05 & 11.36 & 7.20 & -202450.36 & -1128283.62 \\
\hline
\end{tabular}




\subsection{Results and Discussion}

As earlier mentioned, the first step in our analysis consists in deriving the cationic and anionic QSARs that link the structural lipophilic-electronic-steric parameters of the ionic liquids of Figure 2 and Table 2 with the observed activities of the whole containing ionic liquids upon the Vibrio fischeri species. The results are presented in Tables 3 and 4 for the cationic and anionic subsystems for all main combinations, i.e. generating the uni-modes $I a$-to- $I c$ when only one structural parameter is correlated, the two-modes IIa-to-IIc when two combined structural factors are taken into account and for the three-mode correlation III with all structural factors involved, respectively. For each such mode of action, the associated endpoint norm, the statistic and algebraic correlation factors were reported, computed with the equations (6), (7), and (8), respectively.

Table 3: Spectral structure activity relationships (S-SAR) of the ionic liquids of Figure 2 against Vibrio fischeri toxicity, and the associated computed spectral norms with $\left\|\mid Y_{E X P}>\right\|=4.41537$, statistic and algebraic correlation factors, computed upon the relations (6), (7), and (8), throughout the possible correlation models considered from the cationic data in Table 2 , respectively.

\begin{tabular}{|c|c|c|c|c|c|}
\hline Mode & Vectors & Cationic S-SAR & $\left.\| Y_{C}\right\rangle^{\text {Mode }}$ & $r_{S-S A R}^{\text {STATISTIC }}$ & $r_{S-S A R}^{A L G E B R A I C}$ \\
\hline$I a$ & $\begin{array}{l}\left|X_{0}\right\rangle \\
\left|X_{1 C}\right\rangle\end{array}$ & $\begin{array}{c}\left|Y_{C}\right\rangle^{I a}=0.152926\left|X_{0}\right\rangle \\
-0.124263\left|X_{1 C}\right\rangle\end{array}$ & 1.47807 & 0.267342 & 0.334755 \\
\hline$I b$ & $\begin{array}{l}\left|X_{0}\right\rangle \\
\left|X_{2 C}\right\rangle\end{array}$ & $\begin{array}{c}\left|Y_{C}\right\rangle^{I b}=0.0998011\left|X_{0}\right\rangle \\
-0.0129369\left|X_{2 C}\right\rangle\end{array}$ & 1.08531 & 0.132169 & 0.245803 \\
\hline$I c$ & $\begin{array}{l}\left|X_{0}\right\rangle \\
\left|X_{3 C}\right\rangle\end{array}$ & $\begin{array}{l}\left|Y_{C}\right\rangle^{I c}=-0.106319\left|X_{0}\right\rangle \\
\quad+2.57881 \cdot 10^{-7}\left|X_{3 C}\right\rangle\end{array}$ & 0.9452 & 0.0469985 & 0.21407 \\
\hline IIa & $\begin{array}{c}\left|X_{0}\right\rangle \\
\left|X_{1 C}\right\rangle,\left|X_{2 C}\right\rangle\end{array}$ & $\begin{array}{c}\left|Y_{C}\right\rangle^{I I a}=-0.195021\left|X_{0}\right\rangle \\
-0.241666\left|X_{1 C}\right\rangle+0.0295874\left|X_{2 C}\right\rangle\end{array}$ & 1.64279 & 0.314715 & 0.372062 \\
\hline IIb & $\begin{array}{c}\left|X_{0}\right\rangle \\
\left|X_{1 C}\right\rangle,\left|X_{3 C}\right\rangle\end{array}$ & $\begin{array}{c}\left|Y_{C}\right\rangle^{I I b}=-0.139788\left|X_{0}\right\rangle \\
-0.222688\left|X_{1 C}\right\rangle-1.62349 \cdot 10^{-6}\left|X_{3 C}\right\rangle\end{array}$ & 1.72651 & 0.3379 & 0.391023 \\
\hline IIc & $\begin{array}{c}\left|X_{0}\right\rangle \\
\left|X_{2 C}\right\rangle,\left|X_{3 C}\right\rangle\end{array}$ & $\begin{array}{c}\left|Y_{C}\right\rangle^{I I c}=0.384457\left|X_{0}\right\rangle \\
-0.124625\left|X_{2 C}\right\rangle-6.48599 \cdot 10^{-6}\left|X_{3 C}\right\rangle\end{array}$ & 1.71867 & 0.335748 & 0.389246 \\
\hline III & $\begin{array}{c}\left|X_{0}\right\rangle \\
\left|X_{1 C}\right\rangle,\left|X_{2 C}\right\rangle \\
\left|X_{3 C}\right\rangle\end{array}$ & $\begin{array}{c}\left|Y_{C}\right\rangle^{I I I}=0.141278\left|X_{0}\right\rangle \\
-0.127251\left|X_{1 C}\right\rangle-0.0677301\left|X_{2 C}\right\rangle \\
-4.48229 \cdot 10^{-6}\left|X_{3 C}\right\rangle\end{array}$ & 1.79053 & 0.355322 & 0.405522 \\
\hline
\end{tabular}

As a general observation, in all cases there was recorded a systematic increase of the correlation factor when computed in spectral space, i.e. using the algebraic definition, as compared with the standard statistical values. We would like to take this opportunity to advocate the use of the algebraic definition instead of the statistical one since the first one has the physical meaning of the "length of 
action" respecting the old-fashioned dispersion analysis. Nevertheless, dispersion being a consequence of the appropriateness of the fit, the vectorial norm or the "length of action" accounts merely for the degree with which a certain model approaches the observed, or measured or manifested (chemicalbiological) interaction. In this respect, it is also worth noting that both cationic and anionic predicted activities poorly resemble the experimentally expected activities with a smooth increase on the anionic influence, for all computed models except two cases based on the lipophylicity correlation (Ia and IIa).

Apparently, this behaviour disagrees with the previously reported studies in which the anionic effect was only marginal in cytotoxicity $[1,4,26]$, but in some special cases of certain ionic liquids tests [7].

Table 4: Spectral structure activity relationships (S-SAR) of the ionic liquids of Figure 2 against Vibrio fischeri toxicity, and the associated computed spectral norms with $\left\|\mid Y_{E X P}>\right\|=4.41537$, statistic and algebraic correlation factors, computed upon the relations (6), (7), and (8), through all possible correlation models considered from the anionic data in Table 2, respectively.

\begin{tabular}{|c|c|c|c|c|c|}
\hline Mode & Vectors & Anionic S-SAR & $\|\left|Y_{A}\right\rangle^{\text {Mode }}$ & $r_{S-S A R}^{\text {STATISTIC }}$ & $r_{S-S A R}^{A L G E B R A I C}$ \\
\hline$I a$ & $\begin{array}{l}\left|X_{0}\right\rangle \\
\left|X_{1 A}\right\rangle\end{array}$ & $\begin{array}{c}\left|Y_{A}\right\rangle^{I a}=-0.514106\left|X_{0}\right\rangle \\
+0.291698\left|X_{1 A}\right\rangle\end{array}$ & 1.38453 & 0.238974 & 0.313569 \\
\hline$I b$ & $\begin{array}{l}\left|X_{0}\right\rangle \\
\left|X_{2 A}\right\rangle\end{array}$ & $\begin{array}{l}\left|Y_{A}\right\rangle^{I b}=-0.703086\left|X_{0}\right\rangle \\
+0.122745\left|X_{2 A}\right\rangle\end{array}$ & 1.48745 & 0.270118 & 0.33688 \\
\hline$I c$ & $\begin{array}{l}\left|X_{0}\right\rangle \\
\left|X_{3 A}\right\rangle\end{array}$ & $\begin{array}{l}\left|Y_{A}\right\rangle^{I c}=0.376373\left|X_{0}\right\rangle \\
+5.11098 \cdot 10^{-7}\left|X_{3 A}\right\rangle\end{array}$ & 1.75453 & 0.345553 & 0.397368 \\
\hline$I I a$ & $\begin{array}{c}\left|X_{0}\right\rangle \\
\left|X_{1 A}\right\rangle,\left|X_{2 A}\right\rangle\end{array}$ & $\begin{array}{c}\left|Y_{A}\right\rangle^{I I a}=-0.713422\left|X_{0}\right\rangle \\
+0.131985\left|X_{1 A}\right\rangle+0.0904438\left|X_{2 A}\right\rangle\end{array}$ & 1.52849 & 0.282139 & 0.346174 \\
\hline$I I b$ & $\begin{array}{c}\left|X_{0}\right\rangle \\
\left|X_{1 A}\right\rangle,\left|X_{3 A}\right\rangle\end{array}$ & $\begin{array}{c}\left|Y_{A}\right\rangle^{I I b}=0.055315\left|X_{0}\right\rangle \\
+0.359176\left|X_{1 A}\right\rangle+5.73182 \cdot 10^{-7}\left|X_{3 A}\right\rangle\end{array}$ & 2.15865 & 0.451919 & 0.488893 \\
\hline IIc & $\begin{array}{c}\left|X_{0}\right\rangle \\
\left|X_{2 A}\right\rangle,\left|X_{3 A}\right\rangle\end{array}$ & $\begin{array}{c}\left|Y_{A}\right\rangle^{I I c}=0.0132641\left|X_{0}\right\rangle \\
+0.0618883\left|X_{2 A}\right\rangle+4.14933 \cdot 10^{-7}\left|X_{3 A}\right\rangle\end{array}$ & 1.82903 & 0.365689 & 0.414242 \\
\hline$I I I$ & $\begin{array}{c}\left|X_{0}\right\rangle \\
\left|X_{1 A}\right\rangle,\left|X_{2 A}\right\rangle \\
\left|X_{3 A}\right\rangle\end{array}$ & $\begin{array}{c}\left|Y_{A}\right\rangle^{I I I}=0.912459\left|X_{0}\right\rangle \\
+0.776175\left|X_{1 A}\right\rangle-0.209622\left|X_{2 A}\right\rangle \\
+9.70982 \cdot 10^{-7}\left|X_{3 A}\right\rangle\end{array}$ & 2.36461 & 0.504184 & 0.53554 \\
\hline
\end{tabular}

This situation was based on the observation that, for instance, since imidazolium ring in cations is a delocalized aromatic system with high electron acceptor potential, the nitrogen atoms are not capable to form any hydrogen bonds and the result is a very rigid and sterically inflexible system, while the elongation of R2 residue in side chain leads to a continuous increase of flexibility implying more conformational freedom [19]. The reason for this actions relies on the fragmental hydrophobicity of 
each carbon connected to a quaternary amine which, combining the geometric bond factor (that applies to the neutral solute) with a negative electronic bond factor, decreases its magnitude with the square of the distance from the central nitrogen atom [26,27].

Table 5: Spectral structure activity relationships (S-SAR) of the ionic liquids of Figure 2 against Vibrio fischeri toxicity, and the associated computed spectral norms with $\left\|\mid Y_{E X P}>\right\|=4.41537$, statistic and algebraic correlation factors, computed upon the relations (6), (7), and (8), through all possible correlation models considered for the cationicanionic interaction (11), respectively.

\begin{tabular}{|c|c|c|c|c|}
\hline Mode & Ionic Liquid S-SAR & $\left|Y_{A C}\right\rangle^{\text {Mode }}$ & $r_{S-S A R}^{\text {STATISTIC }}$ & $r_{S-S A R}^{A L G E B R A I C}$ \\
\hline$I a$ & $\begin{array}{c}\left|Y_{A C}\right\rangle^{I a}=0.36118\left|X_{0}\right\rangle \\
-0.124263\left|X_{1 C}\right\rangle+0.291698\left|X_{1 A}\right\rangle\end{array}$ & 2.58965 & 0.185959 & 0.586507 \\
\hline$I b$ & $\begin{array}{c}\left|Y_{A C}\right\rangle^{I b}=-0.603285\left|X_{0}\right\rangle \\
-0.0129369\left|X_{2 C}\right\rangle+0.122745\left|X_{2 A}\right\rangle\end{array}$ & 2.30825 & 0.179482 & 0.522776 \\
\hline$I c$ & $\begin{array}{c}\left|Y_{A C}\right\rangle^{I c}=0.270054\left|X_{0}\right\rangle \\
+2.57881 \cdot 10^{-7}\left|X_{3 C}\right\rangle+5.11098 \cdot 10^{-7}\left|X_{3 A}\right\rangle\end{array}$ & 2.41575 & 0.259502 & 0.547123 \\
\hline IIa & $\begin{array}{c}\left|Y_{A C}\right\rangle^{I I a}=0.908443\left|X_{0}\right\rangle \\
-0.241666\left|X_{1 C}\right\rangle+0.131985\left|X_{1 A}\right\rangle \\
+0.0295874\left|X_{2 C}\right\rangle+0.0904438\left|X_{2 A}\right\rangle\end{array}$ & 2.88368 & 0.219986 & 0.653101 \\
\hline$I I b$ & $\begin{array}{c}\left|Y_{A C}\right\rangle^{I I b}=-0.084473\left|X_{0}\right\rangle \\
-0.222688\left|X_{1 C}\right\rangle+0.359176\left|X_{1 A}\right\rangle \\
-1.62349 \cdot 10^{-6}\left|X_{3 C}\right\rangle+5.73182 \cdot 10^{-7}\left|X_{3 A}\right\rangle\end{array}$ & 3.48056 & 0.352356 & 0.788283 \\
\hline IIc & $\begin{array}{c}\left|Y_{A C}\right\rangle^{I I c}=0.397721\left|X_{0}\right\rangle \\
-0.124625\left|X_{2 C}\right\rangle+0.0618883\left|X_{2 A}\right\rangle \\
-6.48599 \cdot 10^{-6}\left|X_{3 C}\right\rangle+4.14933 \cdot 10^{-7}\left|X_{3 A}\right\rangle\end{array}$ & 3.17318 & 0.299925 & 0.718667 \\
\hline III & $\begin{array}{c}\left|Y_{A C}\right\rangle^{I I I}=1.05374\left|X_{0}\right\rangle \\
-0.127251\left|X_{1 C}\right\rangle+0.776175\left|X_{1 A}\right\rangle \\
-0.0677301\left|X_{2 C}\right\rangle-0.209622\left|X_{2 A}\right\rangle \\
-4.48229 \cdot 10^{-6}\left|X_{3 C}\right\rangle+9.70982 \cdot 10^{-7}\left|X_{3 A}\right\rangle\end{array}$ & 3.7151 & 0.397148 & 0.841402 \\
\hline
\end{tabular}

Moreover, the systematic variation of R1, R2, etc., at identical head groups and anions, in all published data, from the molecular to individual organism level, leads to the conclusion that the shorter the chain lengths of side chains the lower the cytotoxicity (higher EC50 values) [7,9]. The electronic portion of the bond factor extends along a chain of no more than 5 alkane carbons causes a decrease in overall hydrophobicity so the chains longer than 5-6 atom carbons will have a greater permeability through the cell membrane (see for example [DMIM][BF4]) [26]. This, probably because 
the chemical transformation of the side chains of ionic liquids may reduce toxicity as far as the metabolites are less toxic compared to their parent chemicals [7].

Table 6: The variation of the cosines of the anion-cationic correlation angle in vectorial space, according with the Eq. (15), for all considered modes of action of the ionic liquids of Figure 2 with the cationic and anionic subsystems S-SAR activities given in Tables 3 and 4, respectively.

\begin{tabular}{cccccccc}
\hline \hline Mode & $I a$ & Ib & Ic & IIa & IIb & IIc & III \\
$\cos \boldsymbol{\theta}_{\boldsymbol{A C}}$ & 0.66397 & 0.600124 & 0.562018 & 0.653248 & 0.60019 & 0.599635 & 0.591015 \\
\hline \hline
\end{tabular}

Next, aiming to combine the two somewhat separate effects of cations and anions in the ionic liquid activities, the spectral-SAR results are given in the Table 5, showing the working ionic liquid QSAR equation as well the actual vectorial norm, statistic and algebraic correlation factors for each mode of action envisaged so far.

The data in Table 5 clearly demonstrate that the ionic liquid S-SAR models always predict higher norms in endpoint activities thus providing the considerable increase in the algebraic correlation factors with respect to the cationic and anionic subsystem effects. It is very interesting to see that the statistical values not only furnish lower values than the algebraic outputs for the ionic liquids, but often lie even below the corresponding statistical values of the cationic and anionic subsystems. This situation gives us a chance to establish the limits of using the dispersion based correlation factor definition since it does not properly reproduced the addition effect of the two interacting subsystems as the anionic-cationic interaction in the ionic liquid structures. On the other hand, the mixture effect of the cationic and anionic vectorial actions in (eco)toxicological studies is well established as far as the single substances of a mixture acts in similar and close quantified manner in all considered modes.

The fact that this is the present case can be firstly visualized by the close inspection of Tables 3 and 4 where the spectral norms of the predicted activities feature close values in relatively narrow domain of actions. Moreover, the reinforcement of this idea comes from the data of Table 6 in which the angle of interactions between the cationic and anionic subsystems are computed, as given by the formula (15), for all considered endpoints with almost constant values around the 0.600 cosines of the angle, while the only higher fluctuation deviation appears in the Ia and IIa cases - the same previously evidenced for the cationic dominancy over the anion effects.

Overall, once the electronic and steric mechanisms have also been considered, the anion could play a central role as technicophore because it exhibits a high potential for change technological properties (solubility, viscosity) or due its peculiarity to partially decompose itself in the ion pair interaction $[26,28]$, leading to its dominant effect in the chemical-biological engaged activity.

With these consideration we can safely assume that the Spectral-SAR in general and the algebraic correlation factors in particular are especially suited for modelling the (eco)toxicological activities of ionic liquids from its anionic and cationic component effects. 
Table 7: Synopsis of the statistic and algebraic values of paths connecting the S-SAR models of Table 5, in the norm-correlation spectral-space of Figure 3, for the ionic liquids of Figure 2 against Vibrio fischeri toxicity. The primary, secondary and tertiary the so called alpha $(\alpha)$, beta $(\beta)$ and gamma $(\gamma)$ paths, are indicated according to the least path principle in spectral norm-correlation space with the statistic and algebraic variants of the correlation factors used, respectively.

\begin{tabular}{|c|c|c|c|c|c|c|}
\hline \multirow{3}{*}{ Path } & \multicolumn{6}{|c|}{ Value } \\
\hline & \multicolumn{2}{|c|}{ Cationic } & \multicolumn{2}{|c|}{ Anionic } & \multicolumn{2}{|c|}{ Ionic Liquid } \\
\hline & statistic & algebraic & statistic & algebraic & statistic & algebraic \\
\hline Ia-IIa-III & 0.324618 & $0.320376 \alpha$ & 1.0154 & 1.0049 & 1.14608 & $1.15396 a$ \\
\hline$I a-I I b-I I I$ & 0.324616 & 0.320376 & 1.01536 & 1.0049 & $1.1451 \alpha$ & 1.15396 \\
\hline Ia-IIc-III & $0.324616 a$ & 0.320376 & 1.01541 & 1.0049 & 1.14513 & 1.15396 \\
\hline$I b-I I a-I I I$ & 0.739827 & 0.723082 & $0.907864 \beta$ & $0.899373 \beta$ & 1.42694 & 1.44248 \\
\hline$I b-I I b-I I I$ & 0.739746 & 0.723082 & 0.907871 & 0.899373 & 1.42377 & 1.44248 g \\
\hline$I b-I I c-I I I$ & 0.739754 & $0.723082 B$ & 0.907893 & 0.899373 & 1.42385 & 1.44248 \\
\hline Ic-IIa-III & 0.900418 & 0.86674 & 1.09986 & 1.08906 & 1.31968 & 1.33226 \\
\hline$I c-I I b-I I I$ & 0.900057 & 0.86674 & 0.630373 & 0.625533 & 1.30763 & 1.33226 \\
\hline$I c-I I c-I I I$ & 0.90009 & 0.86674 & $0.630371 a$ & $0.625533 a$ & $1.30908 \beta$ & $1.33226 \beta$ \\
\hline
\end{tabular}

The final part of discussion is devoted for picturing a mechanistically mode of action for cationic, anionic and of their summed effects in containing ionic liquids on the considered Vibrio fischeri species. That is, the minimum path procedure among all possible ways connecting endpoints from each category of models (i.e. with one, two or three factors dependency) is to be considered. The path lengths were computed employing the equation (10) to all cationic, anionic and ionic liquids data of Tables 3, 4, and 5, and the results are displayed in the Table 7, respectively.

However, in order to identify the shortest paths in each category of endpoint connections, the following rules are applied: the first choice is the overall minimum path in a certain column of Table 7 (i.e. a system with a specific way of correlation factor); if the overall minimum belongs to many equivalent paths (as is the case of cationic with algebraic factor column in Table 7, for instance) the minimum path will be considered the one that links the starting endpoint with the closest endpoint in the sense of norms (as is the norm of IIa mode the closest to the norm of Ia mode in cationic-algebraic column of Table 7, for example); the overall minimum path will set the dominant hierarchy of the mechanistically mode of action towards the experimentally observed activity and will be called the alpha path $(\alpha)$; once the alpha path has been set the next minimum path will be looked for such that the starting endpoint should be different from the one involved in the alpha path (that is, if in the alpha path the starting end point was $I a$, the next path to be identified will begin either from the $I b$ or the $I c$ mode); the next minimum paths are chosen on the same rules as before and will be called as beta and 
gamma paths, $\beta$ and $\gamma$, respectively. At the end of this procedure each mode of action is "touched" only once, except for the final endpoint, here III (as a computational substitute of EXP), so that all the methodology being regarded as searching minimum path throughout variation of paths with the fixed final endpoint. Now, the alpha, beta and gamma path can be easily identified in Table 7 and there are accordingly marked.

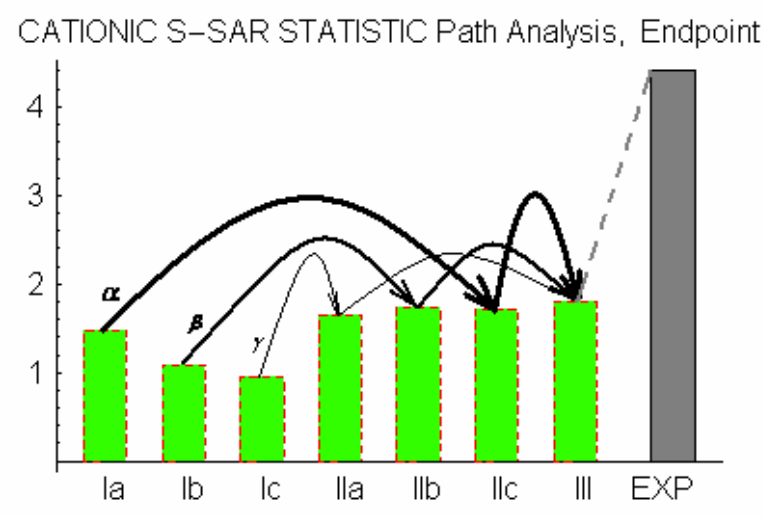

ANIONIC S-SAR STATISTIC Path Analysis, Endpoint

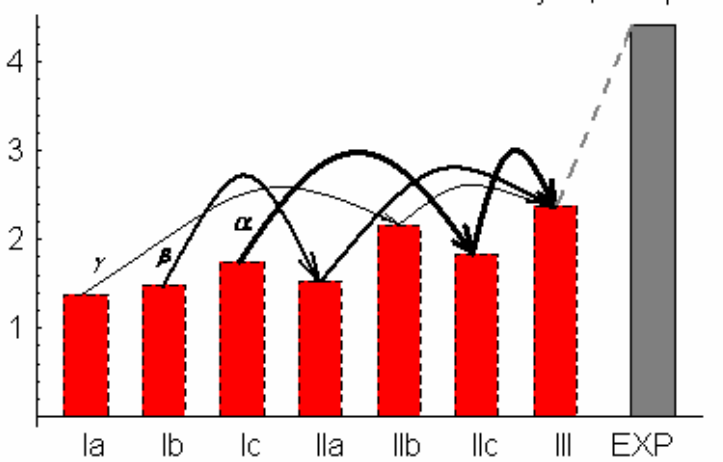

IONIC LIQUID S-SAR STATISTIC Path Analysis, Endpoint

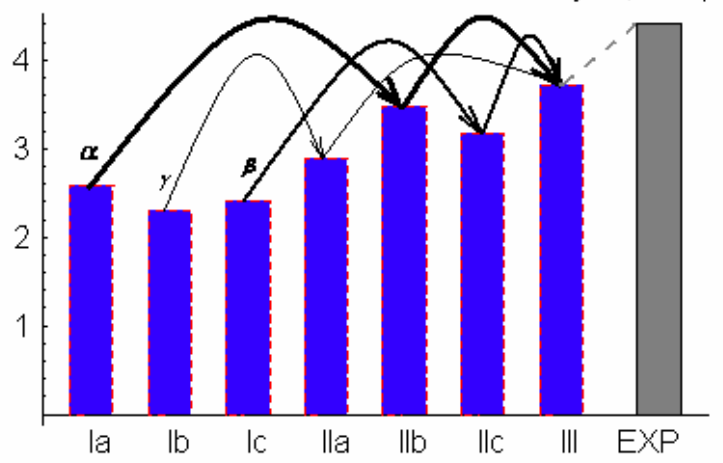

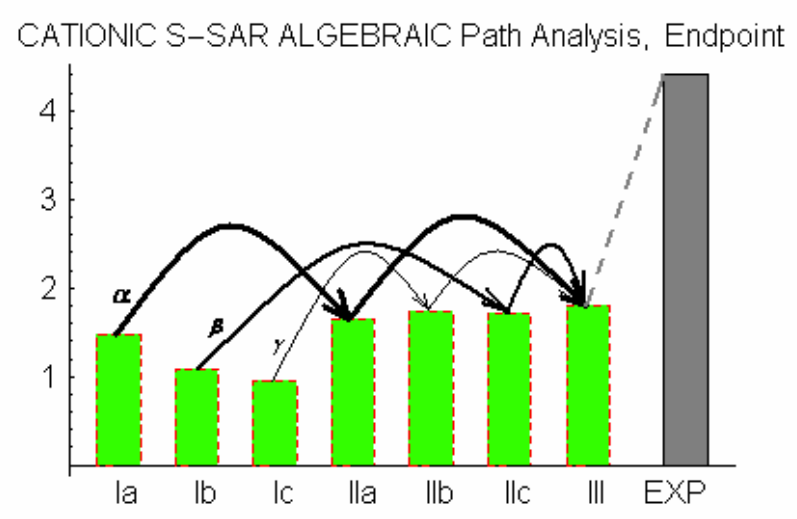

ANIONIC S-SAR ALGEBRAIC Path Analysis, Endpoint

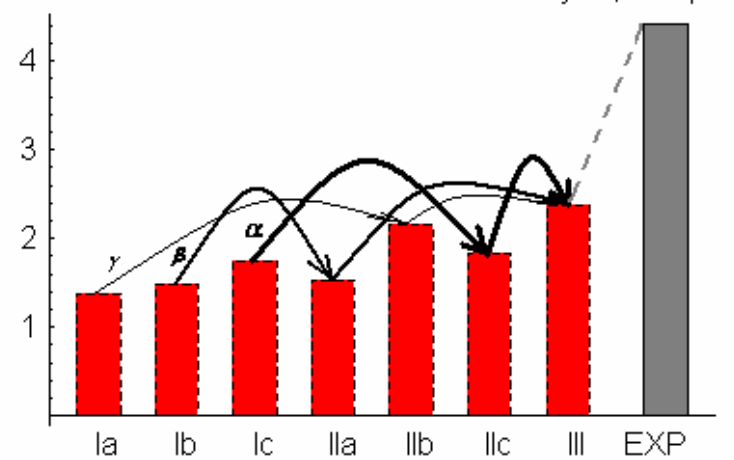

IONIC LIQUID S-SAR ALGEBRAIC Path Analysis, Endpoint

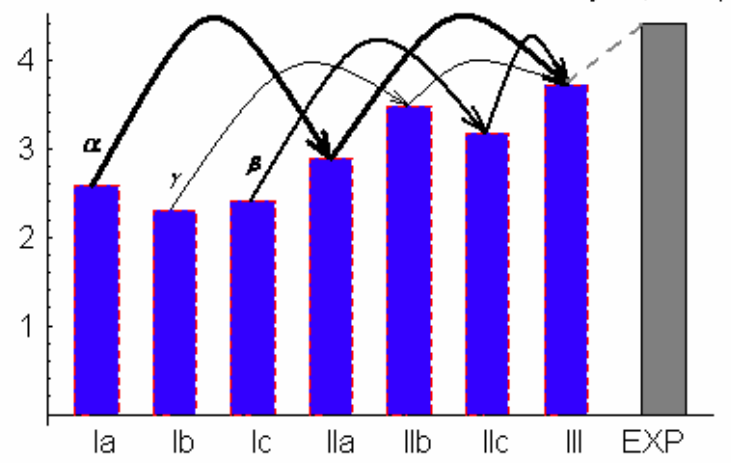

Figure 3: The spectral representation of the chemical-biological interaction paths across the S-SAR to the modeled endpoints of the Vibrio fischeri, according to the least (shortest) path rule within the spectral norm-correlation space applied on Table 7 data, for the cationic, anionic and resulted ionic liquid norms of Tables 3-5, for the statistic and algebraic versions of correlation factors, from up to down and left to right, respectively. The primary-alpha, secondary-beta and tertiary-gamma path hierarchies of Table 7 are indicated by decreasing the thickness of the connecting lines.

With the aim of giving the complete results of the analysis in a single shot, Figure 3 is a "spectral" representation of the data, with the norms for each cationic, anionic, and resulted cationic liquid being 
drawn, linked by the major hierarchical paths against the considered mode of actions toward the observed "length" (norm) of the toxicity activity of the Vibrio fischeri species, for both statistical and algebraic correlation pictures. Figure 7 clearly underlines the fact that while anionic and cationic activity tendencies are somewhat complementary, they do not cancel each other in the ionic liquid that contains them but add up to attain the overall observed toxicity, in the spectral norm - correlation factor space. Besides this, some other useful information can be extracted from Figure 7 concerning the major path of structural causes in manifested toxicological action as revealed bellow.

While in cationic case the statistical and algebraic path does not coincide at all (e.g. what the alpha $I a-I I c-I I I$ path in statistic differs than the alpha Ia-IIa-III path in algebraic views), in the anionic case they are identically predicted (excepting the fact that in the algebraic case the shortened paths are registered), together providing a mixed behavior for the resulted ionic liquid (only the beta path Ic-IIc$I I I$ is overlapping between statistic and algebraic views). While in cationic and anionic subsystems the path hierarchies are reversed, as $\alpha \rightarrow \beta \rightarrow \gamma$ and $\gamma \rightarrow \beta \rightarrow \alpha$, in the resulting ionic liquid again the mixture effect is recorded since the succession $\alpha \rightarrow \gamma \rightarrow \beta$, against the successions of starting endpoints $I a \rightarrow I b \rightarrow I c$, respectively. It is worth pointing out here that, indeed, the cationic alpha path is started on the lipophylicity causes $(I a)$, the same as for the containing ionic liquid, a different situation arising for the alpha anionic path that is beginning with the steric influence $(I c)$. This way the previously noted dominance of cationic influence when correlated with lipophylicity as well the recorded anionic influence related with steric effects are in this picture theoretically confirmed.

Other interesting features about ecotoxicological paths rely on the fact that, while for cationic and anionic subsystems the algebraic paths are systematically lower that the corresponding statistical ones, in the ionic liquid case the situation is reversed. The interpretation of this fascinating result is that it also confirms that the chemical-biological ionic liquid dispersive (not specific) actions in environment are merely through its subsystem components than from itself as a whole. This result further motivates the design of ionic liquids by tailoring the properties of its containing anionic and cationic components for prevent their hazardous toxicity.

Finally, let us also note that the ecotoxicological paths in cationic and anionic subsystems are summed up in the paths of the corresponding ionic liquids in a not trivial ways:

$$
\begin{aligned}
& \alpha_{C}+\gamma_{A}=\alpha_{A C}, \\
& \beta_{C}+\beta_{A}=\gamma_{A C}, \\
& \gamma_{C}+\alpha_{A}=\beta_{A C} .
\end{aligned}
$$

From these S-SAR equations some conceptual, however computationally based, ecotoxicological path rules for ionic liquids can be concluded, namely:

- the anionic gamma path effect is marginal over the cationic alpha path - equation (19);

- the cationic and anionic beta paths decay into the gamma ionic liquid path when met together so that recording a sort of reciprocal cancellation of their effects - equation (20);

- the anionic alpha path effect is reinforcing over the cationic gamma path averaging both at the beta path level of the resulted ionic liquid - equation (21). 
This way, the S-SAR model presented seems to provide a unitary picture of the anionic-cationic interaction in ionic liquids as conciliating the anionic and cationic effects observed so far. However, further studies on different species with diverse computation schemes and parameters are required in order to conceptually asses a definitely [a definitive] theory of ionic liquid inter- and intra- mode of action.

\section{Conclusions}

Despite the promise to change "the face" of organic chemistry, the ionic liquids are becoming a central issue in green chemistry as well, due to their unique physico-chemical properties. For instance, their high viscosities compared with conventional molecular solvents have impact on lowering the reaction rates while through their higher degree of immersion into ground soil and sediments the ecotoxicity of various species and organisms are recorded. The latter effects are based on their common supposed mechanism through membrane disruption: having structural similarity with detergents, pesticides and antibiotics [4,20,29,30] they induce polar narcosis due to their interfacial properties and may cause membrane-bond protein disruption [2,24]. Ionic liquids modes of action are based on the fact that the disrupt membranes and hydrophobic molecules have a greater ability to accumulate at this interface [9], while other mechanisms may arise from acetylcholinesterase inhibition [31], from common cellular structure or processes [4], from structural DNA damage [23, 32]. Eventually, some bacteria could potentially break down imidazolium into different metabolites which follow further inhibition on themselves [1]. In any case, low lipophylicity imidazolium based ionic liquids values indicate low permeability of these ionic liquids [2]. In addition, to the certain role that the lipophylicity has in the assessment of ionic liquid toxicity on various species, before constructing kit- or battery tests involving chemical-biological level of organization, from enzyme to cellular to short and long lived organism [2,4,7-9,23,24,26,31-44], worth focusing on the quantitative algorithm with the help of which the experimental data will be interpret. This is because, criticized for its lacking in real ecological meaning, the dose-response approach for estimating the lethal effects of toxicants on organisms regulatory norms have been built around LC50 values that can be compared between different toxicants and organisms [2,45], while the statistical correlation factors of the proposed QSARs so far are based on dispersion (i.e. hazardous) action and less accounting on the specific ways of ionic liquids action. In this regard, it is important to know if the tested chemicals could reach the target site into organism in a specifically manner first, so that an extrapolation from in vitro to in vivo is necessarily [31] while other factors like biodegradation and bioaccumulation are necessarily be considered before conclusions are drawn [24,46,47].

Having to consider both specific and hazardous paths of action concerning the environmental risk posed by the newly released ionic liquids the recently introduced Spectral-SAR scheme of quantification of chemical-biological interaction [18] is adapted here to the particular ionic liquid cationic-anionic structural interaction. The present method is based on the previous evaluation of QSARs with specific norms and algebraic correlation factors for cationic and anionic influences followed by their vectorial interference in the spectral norm space. With a short generation lifetime, bacteria is an ideal starting point for ionic liquid structure-activity relationship investigation and serves as a basis for further toxicity tests to higher organisms and more complex systems. 
This way, the S-SAR-IL model adapted here was applied to Vibrio fischeri species, this species being reported as the most resistant to other conventional environmental releasing chemical compounds [21]. The results are promising, confirming at some level of analysis all previous certified facts, the cationic generally dominance [48], the special anionic effects [49], the ionic pair effect [50], etc., adding in an elegant manner the least (or minimum) path rule in the spectral norm-correlation factor space as an effective tool in which the ecotoxicological rules of the ionic liquids can be derived. Worth, however, noted that when choosing the Hansch factors, although there was already pointed out that the use of free enthalpy instead of total energy provides better statistical correlation factors [51], in the present study the total energy was preferred due to its close connection with the sterical effects through the computational geometrical optimization procedure involved. This way, the minimal comprehensive set of QSAR descriptors, i.e. hydrophobic, electronic, and steric, when predict the ecotoxicity endpoints was assured [21]. In this respect, further studies may address the effect of the length of alkyl chain of the imidazolium-based ionic liquid on the activity.

The present approach leaves room for further investigation at both the conceptual and computational levels of expertise when improving the specificity of analysis in terms of considered structural factors and of their SAR combinations or when generalizing it to the eco-design of multiple species battery, respectively.

\section{Acknowledgements}

AML and MVP special thank the Romanian National Council of Scientific Research in Universities CNCSIS for the Grants TD/140/2007 and AT/54/2006-2007, respectively. We also thank our colleague Cristian Chiş from "Babel Center" in Timişoara for the careful reading of the manuscript. Kind thoughts are directed to the anonymous referees for their constructive remarks and suggestions.

\section{References}

1. Pernak, J.; Chwala, P. Synthesis and Anti-Microbial Activities of Choline-Like Quaternary Ammonium Chlorides. Eur. J. Med. Chem. 2003, 38, 1035-1042.

2. Bernot, R.J.; Brueseke, M.A.; Evans-White, M.A.; Lamberti, G.A. Acute and Chronic Toxicity of Imidazolium-Based Ionic Liquids on Daphnia Magna. Environ. Toxicol. Chem. 2005, 24, 87-92.

3. Sheldon, R.A. Green Solvents for Sustainable Organic Synthesis: State of the Art. Green Chem. 2005, 7, 267-278.

4. Docherty, K.M.; Kulpa, C.F.Jr. Toxicity and Antimicrobial Activity of Imidazolium and Pyridinium Ionic Liquids. Green Chem. 2005, 7, 185-189.

5. Freemantle, M. New Frontiers for Ionic Liquids. Chem. Eng. News 2007, 1, 23-26.

6. Anastas, P.T.; Warner, J.C. Green Chemistry Theory and Practice, 1998, Oxford University Press, New York.

7. Jastorff, B.; Molter, K.; Behrend, P.; Bottin-Weber, U.; Filser, J.; Heimers, A.; Ondurschka, B.; Ranke, J.; Scaefer, M.; Schroder, H.; Stark, A.; Stepnowski, P.; Stock, F.; Stormann, R.; Stolte, S.; Welz-Biermann, U.; Ziegert, S. ; Thoming, J. Progress in Evaluation of Risk Potential of Ionic Liquids-Basis for an Eco-design of Sustainable Products. Green Chem. 2005, 7, 362-372. 
8. Wells, A.S.; Coombe, V.T. On the Freshwater Ecotoxicity and Biodegradation Properties of Some Common Ionic Liquids. Org. Process Res. Dev. 2006, 10, 794-798.

9. Garcia, M.T.; Gathergood, N.; Scammells, P.J. Biodegradable Ionic Liquids. Part II. Effect of the Anion and Toxicology. Green Chem. 2005, 7, 9-14.

10. Jain, D.; Kumar, A.; Chauhan, S.; Chauhan, S.M.S. Chemical and Biochemical Transformation in Ionic Liquids. Tetrahedron 2005, 61, 1015-1060.

11. Dupont, J.; Suarez, P.A.Z. Physico-Chemical Processes in Imidazolium Ionic Liquids. Phys. Chem. Chem. Phys. 2006, 8, 2441-2452.

12. Hansen, J.P.; McDonald, I.R. Theory of Simple Liquids 1986, Academic Press, London, 2nd Ed.

13. Scammells, P.J.; Scott, J.L.; Singer, R.D. Ionic Liquids: The Neglected Issues. Aust. J. Chem. 2005, 58, 155-169.

14. Hunt, P.A.; Gould, I.R.; Kirchner, B. The Structure of Imidazolium-Based Ionic Liquids: Insights from Ion-Pair Interactions. Aust. J. Chem. 2007, 60, 9-14.

15. Hunt, P.A.; Kirchner, B.; Welton, T. Characterizing the Electronic Structure of Ionic Liquids: An Examination of the 1-Butyl-3-ethylimidazolium Chloride Ion Pair. Chem. Eur. J. 2006, 12, 67626775.

16. Hunt, P.A.; Gould, I.R. Structural Characterization of the 1-Butyl-3-Methylimidazolium Chloride Ion Pair Using Ab Initio Methods. J. Phys. Chem. A. 2006, 110, 2269-2282.

17. Hunt, P.A. The Simulation of Imidazolium-Based Ionic Liquids. Mol. Simul. 2006, 32, 1-10.

18. Putz, M.V.; Lacrămă, A.-M. Introducing Spectral Structure Activity Relationship (S-SAR) Analysis. Application to Ecotoxicology, Int. J. Mol. Sci. 2007, 8, 363-391.

19. Jastorff, B.; Stormann, R.; Ranke, J.; Molter, K.; Stock, F.; Oberheitmann, B.; Hoffmann, W.; Hoffmann, J.; Nuchter, M.; Ondruschka, B.; Filser, J. How Hazardous are Ionic Liquids? Structure - Activity Relationship and Biologic Testing as Important Elements for Sustainability Evaluation. Green Chem. 2003, 5, 136-142.

20. Pernak, J.; Sobaszkiewicz, K.; Mirska, I. Antimicrobial Activities of Ionic Liquids. Green Chem. 2003, 5, 52-56.

21. Lacrămă, A.M.; Putz, M.V.; Ostafe V. Designing a Spectral Structure-Activity EcotoxicoLogistical Battery, in Advances in Quantum Chemical Bonding Structures, M.V. Putz (Ed.), Research Signpost, 2007, Kerala, India, in press (http://www.trnres.com/putz.htm).

22. National Toxicology Program (NTP) and National Institute of Environmental Health Sciences (NIEHS). Review of Toxicological Literature for Ionic Liquids, 2004, Prepared By Integrated Laboratory Systems Inc., Research Triangle Park.

23. Bernot, R.J.; Kennedy, E.E.; Lamberti, G.A. Effects of Ionic Liquids on the Survival, Movement, and Feeding Behavior of the Freshwater Snail, Physa Acuta. Environ. Toxicol. Chem. 2005, 24, 1759-1765.

24. Couling, D.J.; Bernot, A.R.; Docherty, K.M.; Dixon, J.K.; Maginn, E.J. Assessing the Factors Responsible for Ionic Liquid Toxicity to Aquatic Organisms via Quantitative Structure - Property Relationship Modeling. Green Chem. 2006, 8, 82-90.

25. Hypercube, Inc. 2002, HyperChem 7.01, Program package.

26. Stepnowski, P.; Skladanowski, A.C.; Ludwiczak, A.; Laczynska, E. Evaluating the Cytotoxicity of Ionic Liquids Using Human Cell Line Hela. Hum. Exp. Toxicol. 2004, 23, 513-517. 
27. Hansch, C.; Leo, A. Exploring QSAR, 1995, ACS Professional Reference Book. ACS: Washington, DC.

28. Swatloski, R.P.; Holbrey, J.D.; Rogers, R.D. Ionic Liquids Are Not Always Green: Hydrolysis of 1-Butyl-3-Methylimidazolium Hexafluorophosphate. Green Chem. 2003, 5, 361-363.

29. Kamrin, M.A. Pesticide Profiles: Toxicity, Environmental Impact, and Fate, 1997, Lewis Publishers, Boca Raton, Florida.

30. Docherty, K.M.; Hebbeler, S.Z.; Kulpa, C.F.Jr. An Assessment of Ionic Liquid Mutagenicity Using the Ames Test. Green Chem. 2006, 8, 560-567.

31. Stock, F.; Hoffmann, J.; Ranke, J.; Stormann, R.; Ondruschka, B.; Jastorff, B. Effects of Ionic Liquids on the Acetylcholinesterase -A Structure-Activity Relationship Consideration. Green Chem. 2004, 6, 286-290.

32. Raves, M.L.; Harel, M.; Pang, Y.P.; Silman, I.; Kozikowski, A.P.; Sussman, J.L. 3D Structure of Acetylcholinesterase Complexed with the Nootropic Alkaloid, (-)-Huperzine A. Nat. Struct. Biol. 1997, 4, 57-63.

33. Skladanowski, A.C.; Stepnowski, P.; Kleszczynski, K.; Dmochowska, B. AMP Deaminase in Vitro Inhibition by Xenobiotics. A Potential Molecular Method for Risk Assessment of Synthetic Nitro- and Polycyclic Musks, Imidazolium Ionic Liquids and $\mathrm{N}$-Glucopyranosyl Ammonium Salts. Environ. Toxicol. Phar. 2005, 19, 291-296.

34. Ranke, J.; Molter Stock, F.; Bottin-Weber, U.; Poczobutt, J.; Hoffmann, J.; Ondruschka, B.; Filser, J.; Jastorff, B. Biological Effects of Imidazolium Ionic Liquids with Varying Chain Lengths in Acute Vibrio Fischeri and Wst-1 Cell Viability Assays. Ecotoxicol. Environ. Saf. 2004, 58, 396404.

35. Standard Test Method for Assessing the Microbial Detoxification of Chemically Contaminated Water and Soil Using a Toxicity Test with a Luminescent Marine Bacterium. ASTM Designation: D 5660-96, 1996.

36. Kaiser.K.L.E.; Palabrica, V.S. Photobacterium phosphoreum Toxicity Data Index. Water Poll. Res. J. Can. 1991, 26, 361-431.

37. McQueen, D.J.; Post, J.R.; Mills, E.L.; Fish, C.J. Trophic Relationships in Freshwater Pelagic Eco-systems. Can. J. Fish. Aquat. Sci. 1986, 43, 1571-1581.

38. Swatloski, R.P.; Holbrey, J.D.; Memon, S.B.; Caldwell, G.A.; Caldwell, K.A.; Rogers, R.D. Using Caenorhabditis Elegans to Probe Toxicity Of 1-Alkyl-3-Methylimidazolium Chloride Based Ionic Liquids. Chem. Commun. 2004, 668-669.

39. Wong, P.T.; Couture, P. Toxicity Screening Using Phytoplankton.In: Dutka, B.J., Bitton, G. (Eds.). Toxicity Testing Using Microorganisms, 1986, vol. II, CRC Press, Boca Raton, F1, 79-100.

40. Latala, A.; Stepnowski, P.; Nedzi, M.; Mrozik, W. Marine Toxicity Assessment of Imidazolium Ionic Liquids: Acute Effects on the Baltic Algae Oocystis submarina and Cyclotella meneghiniana. Aquat. Toxicol. 2005, 73, 91-98.

41. EN Water Quality_Fresh Water Algal Growth-Inhibition Test with Scenedesmus Subspicatus and Selenastrum Capricornutum (ISO 8692:1993). European Committee for Standardization, 1993, Brussels. 
42. EN Water Quality-Marine Algal Growth-Inhibition Test with Skeletonema Costatum and Phaeodactylum Tricornutum (Iso 10253:1995). European Committee for Standardization, 1995, Brussels.

43. Cross, J. Introduction to Cationic Surfactants: Analytical and Biological Evaluation, 1994, Marcel Dekker, Inc. New York, $3^{\text {rd }}$ Ed.

44. Pretti, C.; Chappe, C.; Pieraccini, D.; Gregori, M.; Abramo, F.; Monni, G.; Intorre, L. Acute Toxicity of Ionic Liquids to The Zebrafish (Danio rerio). Green Chem. 2006, 8, 238-240.

45. Newman, M.; Dixon, P. Ecologically Meaningful Estimates of Lethal Effect in Individuals, in Ecotoxicology: A Hierarchical Treatment., Newman Mc, Jagoe Ch., Eds., Lewis, Boca Raton, U.S.A., 1996, 225-253.

46. Gathergood, N.; Garcia, M.T.; Scammells, P.J. Biodegradable Ionic Liquids: Part I. Concept, preliminary targets and evaluation. Green Chem. 2004, 6, 166-175.

47. Gathergood, N.; Scammells, P.J.; Garcia, M.T. Biodegradable Ionic Liquids. Part III. The First Readily Biodegradable Ionic Liquids. Green Chem. 2006, 8, 156-160.

48. Ropel, R.; Belveze L.S.; Aki, S.N.V.K.; Stadtherr, M.A.; Brennecke, J.F. Octanol-Water Partition Coefficients of Imidazolium-Based Ionic Liquids. Green Chem. 2005, 7, 83-90.

49. Stolte, S.; Arning, J.; Bottin-Weber, U.; Matzke, M.; Stock, F.; Thiele, K.; Uerdingen, M.; WelzBiermann, U.; Jastorff, B. ; Ranke, J. Anion Effects on the Cytotoxicity of Ionic Liquids. Green Chem. 2006, 8, 621-629.

50. Shugart, L. Molecular Markers to Toxic Agents. In Ecotoxicology: A Hierarchical Treatment. Newman Mc, Jagoe Ch., Eds., Lewis, Boca Raton, Fl, 1996, 133-161.

51. Stiefl, N.; Bauman, K. Structure-Based Validation of the 3D-QSAR Technique MaP. J. Chem. Inf. Mod. 2005, 45, 739-749.

(C) 2007 by MDPI (http://www.mdpi.org). Reproduction is permitted for noncommercial purposes. 